\title{
ASO Visual Abstract: Quality Standards for Surgery of Colorectal Peritoneal Metastasis After Cytoreductive Surgery and Hyperthermic Intraperitoneal Chemotherapy
}

\author{
Alfonso García Fadrique, MD, PhD ${ }^{1}$, Rafeal Estevan Estevan, $\mathrm{MD}, \mathrm{PhD}^{1}$, and Luis Sabater Ortí, MD, $\mathrm{PhD}^{2}$ \\ ${ }^{1}$ Valencian Institute of Oncology, General and Gastrointestinal Surgery, Valencia, Spain; ${ }^{2}$ Department of Surgery, \\ Biomedical Research Institute INCLIVA, Hospital Clínico Universitario, University of Valencia, Valencia, Spain
}

The authors report a study to assess quality standards in cytoreductive surgery (CRS) and hyperthermic intraperitoneal chemotherapy (HIPEC) for colorectal peritoneal metastases to objectively classify surgical results as desirable (https://doi.org/10.1245/s10434-021-10642-6). The current data are of main relevance for future randomized studies as well as for benchmarking among centers.

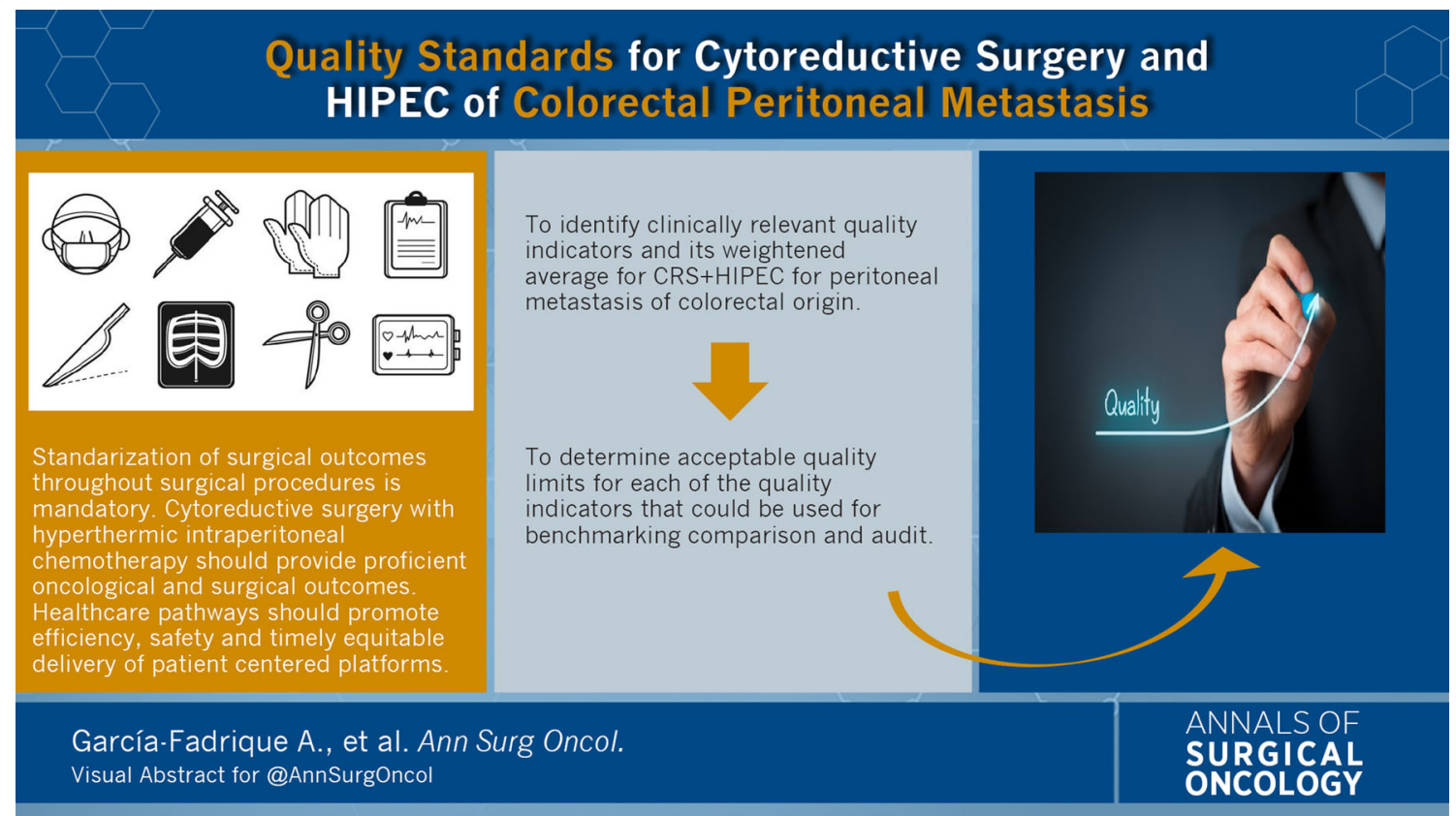

(C) Society of Surgical Oncology 2021

Published Online: 25 August 2021

A. García Fadrique, MD, $\mathrm{PhD}$

e-mail: agarciafadrique@gmail.com
DISCLOSURE There are no conflicts of interest.

Publisher's Note Springer Nature remains neutral with regard to jurisdictional claims in published maps and institutional affiliations. 